Research Paper

\title{
Effect of the Hand Antiseptic Agents Benzalkonium Chloride, Povidone-lodine, Ethanol, and Chlorhexidine Gluconate on Atopic Dermatitis in NC/Nga Mice
}

\author{
Kaori Sadakane ${ }^{\bowtie}$ and Takamichi Ichinose \\ Department of Health Sciences, Oita University of Nursing and Health Sciences, 2944-9 Megusuno, Oita City, Oita 870-1201, Japan \\ $\bowtie$ Corresponding author: Kaori Sadakane. Tel: 81-97-586-4432; Fax: 81-97-586-4386; E-mail: sadakane@oita-nhs.ac.jp \\ (c) Ivyspring International Publisher. This is an open-access article distributed under the terms of the Creative Commons License (http://creativecommons.org/ \\ licenses/by-nc-nd/3.0/). Reproduction is permitted for personal, noncommercial use, provided that the article is in whole, unmodified, and properly cited.
}

Received: 2014.08.13; Accepted: 2014.11.24; Published: 2015.01.05

\begin{abstract}
Antiseptic agents can cause skin irritation and lead to severe problems, especially for individuals with atopic diatheses. We investigated the effect of 4 different antiseptic agents using an atopic dermatitis (AD) model mouse. NC/Nga mice were subcutaneously injected with mite allergen (Dp) to induce AD-like skin lesions (ADSLs), and an application of $0.2 \%(w / v)$ benzalkonium chloride (BZK), 10\% (w/v) povidone-iodine (PVP-I), 80\% (v/v) ethanol $(\mathrm{Et}-\mathrm{OH})$, or $0.5 \%(\mathrm{v} / \mathrm{v})$ chlorhexidine gluconate (CHG) was applied to the ear envelope. BZK induced a significant increase in the severity of the clinical score, infiltration of inflammatory cells, local expression of inflammatory cytokines in subcutaneous tissue, and total serum immunoglobulin (Ig) E. PVP-I increased the clinical score, number of mast cells, and production of inflammatory cytokines, and total serum IgE. Et-OH increased the clinical score and number of inflammatory cells, but showed no effect on serum IgE levels. No differences in any parameters were observed between $\mathrm{CHG}$ and the vehicle. Collectively, the results suggest the severity of the ADSL was related in part to the strength of the immunoreaction. These findings suggest that CHG could offer the lowest risk of inducing ADSL in individuals with atopic dermatitis and that medical staff and food handlers with $A D$ could benefit from its use.
\end{abstract}

Key words: atopic dermatitis, benzalkonium chloride, povidone-iodine, ethanol, chlorhexidine gluconate

\section{Introduction}

The use of cleansers and chemicals is a leading cause of the aggravation of atopic dermatitis (AD) for patients with atopic diatheses. However, disinfection using hand antiseptic agents is essential for medical practitioners and food handlers, even for those with this condition. In current practice, quick-drying hand antiseptic gels are recommended because they are time-saving, easy to use, and provide the same bacterial eradication rate as hand washing with tap water and detergent [1]. An additional advantage is that the quick-drying active ingredients remain on the skin and continue the disinfection effect. However, a potential negative effect is that the active ingredients will irritate the skin because of their continued presence on the skin surface.
As a cationic detergent in the family of quaternary ammonium compounds, benzalkonium chloride (BZK) shows strong antiseptic activity against both gram-positive and -negative bacteria. In terms of skin sensitization, the irritant action of BZK has been shown to be minimal and more gentle than that of ethanol-based antiseptics [2-4]. Hand sanitizers containing BZK are widely available in various settings, including hospitals, restaurants, and shopping centers. However, contact dermatitis due to BZK has been reported. In particular, previous case studies have reported the occurrence of erythematous rash, eczema, and blistering on the face, trunk, and limbs after using shampoo, plaster of Paris bandages, or antiseptic bath oil containing BZK [5-7]. 
Another well-known antiseptic, povidone-iodine (PVP-I), is widely used in mouthwash and in disinfection before surgery. In contrast to other antiseptics with efficacy against spore-forming bacteria, PVP-I shows low toxicity in humans. Moreover, PVP-I is believed to be one of the most effective antiseptics for the prevention of hospital-acquired infection, which might be attributable to its relatively long-term efficacy. Nonetheless, some reports have been published on contact dermatitis due to PVP-I [8-10].

Ethanol $(\mathrm{Et}-\mathrm{OH})$ is the most used of the various available antiseptics. With the exception of some spore-forming bacteria and envelope-lacking viruses, ethanol shows a broad antibacterial and antiviral spectrum. Ethanol-based gels have been strongly recommended for maintaining the hand hygiene of medical experts, since they showed decreased skin irritation compared to hand washing with soap and water [11,12] in addition to their strong disinfecting power. However, Et-OH is also well known to result in rough hands because of its strong defatting effect on the skin. In a cross-sectional survey, most responders $(88 \%$ of 399 responders at a large United Kingdom teaching hospital) who used alcohol gel experienced skin complaints [13].

In addition to these other antiseptics, chlorhexidine gluconate $(\mathrm{CHG})$ also shows a broad antibacterial spectrum. However, CHG does not affect spore-forming bacteria and viruses without envelopes. In addition, although CHG has been reported to induce contact dermatitis, the incidence of this condition is very low $[14,15]$.

A number of studies have investigated the effects of these different antiseptic agents in subjects with normal skin conditions [7-9, 14, 16]. However, the effect of hand disinfectants containing these antiseptic agents on AD remains unclear. Therefore, in this study, we investigated the effects of antiseptics containing BZK, PVP-I, Et-OH, or CHG using an AD mouse model to evaluate the relative response of atopic dermatitis-like skin lesions (ADSLs) in this model.

\section{Materials and Methods}

\subsection{Animals}

Seventy-two 10-week-old male NC/Nga mice were purchased from Japan SLC Inc (Shizuoka, Japan) and maintained under conventional conditions [12 mice per cage, a 12/12-h light/dark cycle, and ad libitum access to water and a commercial diet (CE-2; Japan Clea Co., Tokyo, Japan)] in a facility maintained at a temperature of $23-25^{\circ} \mathrm{C}$ and a humidity of $50-70 \%$. Animal experiments were performed with the approval of the Research Ethics Committee of Oita University of Nursing and Health Sciences.

\subsection{Chemicals}

The BZK, PVP-I, and CHG (20\% aqueous solution) were purchased from Sigma-Aldrich (St. Louis, MO, USA); Et-OH (99.5\% purity) was purchased from Wako Pure Chemical Industries (Osaka, Japan). To determine the dose to use in the administration of these active ingredients, we initially determined which hand antiseptic agents to evaluate by examining which ones were primarily used in 4 hospitals in Oita City and also sold at drug stores. We subsequently researched the concentrations of 4 types of active ingredients (BZK, PVP-I, Et-OH, and CHG) among the hand antiseptic gels or solutions. We also confirmed whether the active ingredients were sold at these concentrations in major commodities at the websites of the product company. Based on this information, we decided to administer BZK, PVP-I, $\mathrm{Et}-\mathrm{OH}$, and CHG at a dose of $0.2 \%(\mathrm{w} / \mathrm{v}), 10 \%(\mathrm{w} / \mathrm{v})$, $80 \%(\mathrm{v} / \mathrm{v})$, and $0.5 \%(\mathrm{v} / \mathrm{v})$, respectively.

Mite crude extract (Dermatophagoides pteronyssinus, Dp; Cosmo Bio Co., Ltd., Tokyo, Japan) was used as an allergen for inducing $\mathrm{AD}$.

\subsection{Experimental design}

The mice were divided into 6 groups as follows: 1) saline + vehicle (control group), 2) Dp + vehicle, 3 ) $\mathrm{Dp}+\mathrm{BZK}$, 4) Dp + PVP-I, 5) Dp + Et-OH, and 6) Dp + CHG. As shown in Figure 1, the animals in the experimental groups were exposed to the allergen through the subcutaneous injection of $5 \mu \mathrm{g}$ of $\mathrm{Dp}$ dissolved in $10 \mu \mathrm{l}$ of saline in the ventral side of the right ear 2 to 3 days a week (a total of 8 times) under anesthesia with $4 \%$ halothane (Takeda Pharmaceutical Co., Ltd., Osaka, Japan). Animals in the control group were not sensitized, receiving a subcutaneous injection of $10 \mu \mathrm{l}$ of saline in the ventral side of the right ear. Animals belonging to the groups receiving an application of antiseptic agent were exposed to the allergen and treated with $0.2 \%(\mathrm{w} / \mathrm{v})$ benzalkonium chloride (Dp + BZK), 10\% (w/v) povidone-iodine (Dp + PVP-I), $80 \%(\mathrm{v} / \mathrm{v})$ ethanol $(\mathrm{Dp}+\mathrm{Et}-\mathrm{OH})$, or $0.5 \%$ $(\mathrm{v} / \mathrm{v})$ chlorhexidine gluconate (Dp $+\mathrm{CHG})$. These agents were applied a total of 15 times during the experimental period (Fig. 1). The BZK, PVP-I, Et-OH, and $\mathrm{CHG}$ were dissolved in $25 \mu \mathrm{l}$ of injection water (Otsuka Pharmaceutical Co., Ltd., Tokyo, Japan) and applied gently to the dorsal side of the right ear using a micropipette with a fine plastic tip. The animals in the Dp + vehicle and control groups received $25 \mu \mathrm{l}$ of injection water. All animals were sacrificed on the last day of the experiment (day 18). 


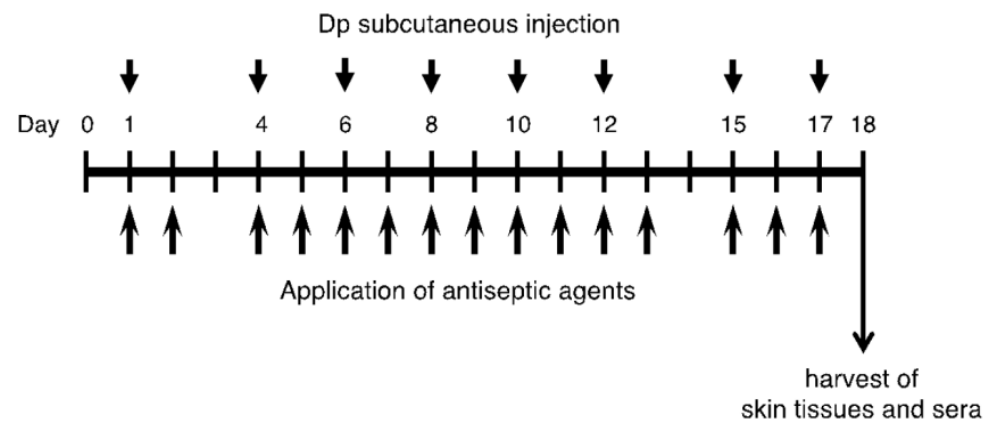

Figure 1. Experimental protocol. Dp; mite crude extract (Dermatophagoides pteronyssinus).

\subsection{Evaluation of skin disease}

Twenty-four hours after each subcutaneous injection, the ear thickness was measured using a gauge (Ozaki Mfg., Tokyo, Japan), and the clinical score for ADSLs was determined using a modification of a previously described method [17] with the individual mouse. The total clinical severity score was defined as the sum of the individual scores for the symptoms measured. The symptoms of skin dryness and eruption were scored as follows: 0 , no symptoms; 0.5 , mild symptoms; 1, moderate symptoms; and 2, severe symptoms. The presence of edema was scored as following: 0 , no symptoms; 0.5 , very mild symptoms; 1 , mild symptoms; 2 , moderate symptoms; and 3 , severe symptoms. Crusting and erosion were scored as follows: 0 , no symptoms; 0.5 , very mild symptoms; 1 , mild symptoms; 2, moderate symptoms; 3, severe symptoms; and 4 , very severe symptoms.

\subsection{Total IgE and Dp-specific IgG measurements}

Serum total IgE was determined with an enzyme-linked immunosorbent assay (ELISA; Mouse IgE ELISA Kit AKRIE-010, Shibayagi, Gunma, Japan) using sera collected from the retro-orbital venous plexus at one day before the first immunization, and at the end of the experimental period by cardiac puncture. The detection limit of this assay was less than $1 \mathrm{ng} / \mathrm{mL}$. The production of total $\mathrm{IgE}$ during the experimental period was defined as the change in the total $\operatorname{IgE}(\Delta$ total $\operatorname{IgE}$ ), which was derived by subtracting the measurement value of the first serum collection point from that of the second one. For purposes of simplifying data presentation, the production of total $\operatorname{IgE}$ is expressed as total $\operatorname{IgE}$ values. The measurement of Dp-specific IgG ${ }_{1}$ antibody in the sera collected by cardiac puncture was performed using previously described protocols [18]. The sera were stored at $-80^{\circ} \mathrm{C}$ for later measurements.

\subsection{Histopathological analysis}

At the end of the experimental period, the ears of 6 mice from each group were removed, fixed in 10\% neutral phosphate-buffered formaldehyde, and cut into 3 segments $\sim 2 \mathrm{~mm}$ in width. After the ear segments were embedded in paraffin, 2 sections $\sim 3 \mu \mathrm{m}$ in thickness were obtained from each one. One of the sections was stained with hematoxylin and eosin, while the other one was stained with toluidine blue. Three points on each segment were arbitrarily selected for indicating the apical, central, and basal regions, and the number of inflammatory cells in the subcutaneous tissue of each of the 9 areas ( 3 ear segments $\times 3$ regions) was counted using a Nikon ECLIPSE 50i light microscope (Nikon Co., Tokyo, Japan). The evaluated area was defined by a perpendicular line extending from the edge of the cartilage of the external ear by a length of $100 \mu \mathrm{m}$ (for eosinophil count) or $400 \mu \mathrm{m}$ (for mast cell count) to the epidermal layer. Mast cell degranulation was scored as previously described [17]: non-degranulated $(0 \%)$, mildly degranulated $(0-50 \%)$, and severely degranulated $(>50 \%)$.

\subsection{Cytokine and chemokine quantification}

At the end of the experimental period, the right ears of 6 mice from each group were removed, homogenized, and centrifuged as previously described [18]. The levels of Interleukin (IL)-1 $\beta$, IL-2, IL-5, IL-10, IL-13, IL-33, keratinocyte chemoattractant (KC), interferon (IFN)- $\gamma$, tumor necrosis factor (TNF)-a, macrophage inflammatory protein (MIP)-1 $\alpha$, regulated on activation, normal $\mathrm{T}$ cell expressed and secreted (RANTES), and eotaxin were determined with the Quantikine ELISA Kit (R\&D Systems, Inc., Minneapolis, MN, USA). IL-18 levels were assessed with the Mouse IL-18 ELISA Kit (Medical \& Biological Laboratories, Co., Ltd., Aichi, Japan). The detection limits of IL-1 $\beta$, IL-2, IL-5, IL-10, IL-13, IL-33, KC, IFN- $\gamma$, TNF-a, MIP-1a, RANTES, eotaxin, and IL-18 were $2.31,3,7$, $4.0,1.5,6.85,2.0,2,1.88,1.5,2.00,3$, and $25 \mathrm{pg} / \mathrm{mL}$, 
respectively. The individual measured values were corrected by the weight of each mouse ear.

\subsection{Statistical analysis}

All statistical analyses were performed using PASW Statistics ver.18 for Macintosh (IBM, Armonk, NY, USA), and the results are reported as the mean \pm standard error. All data were analyzed with a one-way analysis of variance (ANOVA) followed by Tukey's honestly significant difference (HSD) test, with the exception of the data in Figure 2 and Table 1. The clinical ADSL scores were analyzed by two-way repeated measures ANOVA using the day of administration as the within-subject factor and the embrocation as the between-subject factor. The degrees of freedom were adjusted using Greenhouse-Geisser correction. If a significant $F$ ratio was observed for the day $\times$ embrocation interaction, the differences resulting from the administration of different antiseptics were determined by Tukey's HSD test. To analyze the contribution of antiseptic agents to AD-like skin lesions, Pearson's correlation coefficient analysis was performed. A p-value of $<0.05$ was considered an indication of statistical significance.

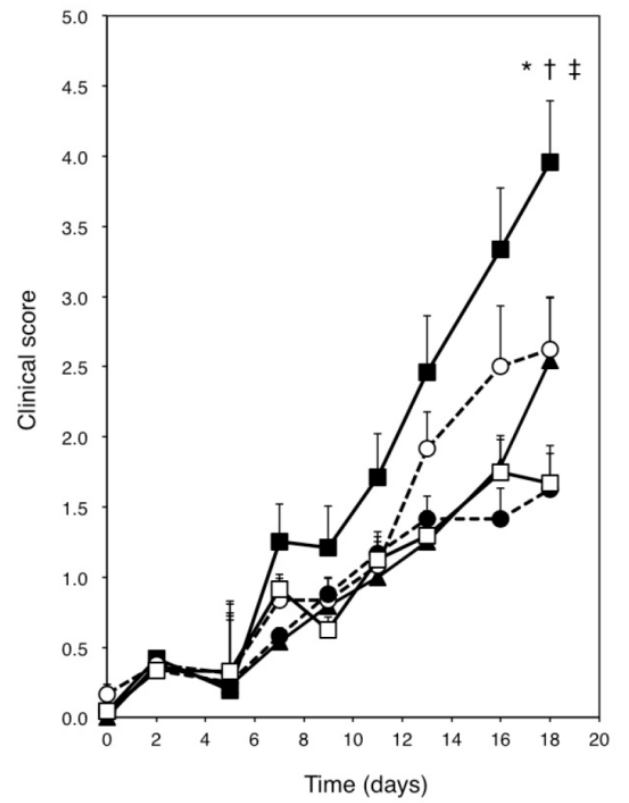

Figure 2. Skin severity scores for the ears of NC/Nga mice. Open square $=D p+$ vehicle; solid square $=D p+B Z K$; open circle $=D p+P V P-I$; solid triangle $=\mathrm{Dp}+\mathrm{Et}-\mathrm{OH}$; solid circle $=\mathrm{Dp}+\mathrm{CHG}$. All data are the mean \pm standard errors $(\mathrm{SE})$ values of 12 mice. ${ }^{*} p<0.01 \mathrm{vs.} \mathrm{Dp}+$ vehicle group, $\dagger p<0.01$ vs. $\mathrm{Dp}+\mathrm{Et}-\mathrm{OH}$ group, and $\ddagger \mathrm{p}<0.01$ vs. $\mathrm{Dp}+\mathrm{CHG}$ group.

\section{Results}

\subsection{Clinical scores}

Figure 3 shows the right ears of mice from the different groups at the end of the experiment. No change was observed in the saline + vehicle group (Fig. 3A). However, dryness, redness, and edema were noted in the Dp + vehicle group (Fig. 3B). Exposure to $\mathrm{Dp}$ and the subsequent administration of BZK, PVP-I, or Et-OH but not CHG resulted in more severe symptoms (e.g., blood crust formation and erosion) as compared to the $\mathrm{Dp}+$ vehicle group (Fig. 3C-F). The Dp-treated groups showed markedly higher clinical scores than the control group, including the clinical scores for dryness, redness, erosion, crust formation, edema, and ear thickening (Fig. 2). The Dp + BZK group showed the highest average score from day 7 to the end of the experimental period, while the Dp + PVP-I group had the second highest average score from day 13 to the end of the experimental period. The average score of the $\mathrm{Dp}+$ Et-OH group was the same as that of the $\mathrm{Dp}+$ vehicle group until the assessment points before the last one, increasing to levels comparable to that of the $\mathrm{Dp}+$ PVP-I group at the final assessment point. The average score of the Dp + CHG group was not significantly different from the $\mathrm{Dp}+$ vehicle group throughout the experimental period.

The $\mathrm{Dp}+$ vehicle and antiseptic groups were analyzed by two-way repeated measures ANOVA to evaluate the contribution of the antiseptics to the ADSL clinical scores. The main effect of antiseptic type was observed to be significant $\left(\mathrm{F}_{(13.0,179.3)}=3.909\right.$, $p=0.00001$ ), indicating the pattern of aggravation as revealed by the skin scores significantly differed among the antiseptics. Moreover, analysis of the effect of the between-subject factor revealed significant differences between the $\mathrm{Dp}+$ vehicle and antiseptic groups $\left(F_{(4,55)}=6.148, p=0.0004\right)$. As shown by Tukey's HSD test, the Dp + BZK group had a significantly increased score as compared to the $\mathrm{Dp}+\mathrm{Et}-\mathrm{OH}, \mathrm{Dp}+$ $\mathrm{CHG}$, and $\mathrm{Dp}+$ vehicle groups $(\mathrm{p}<0.01)$.

\subsection{Inflammation of the subcutaneous tissue}

The dorsal skin of the ear in all Dp-treated groups showed a thickened epidermis and dermis, eosinophil accumulation (Fig. 4A), and mast cell degranulation (Fig. 4B) compared with that of the control group. The eosinophil count in the subcutaneous tissue of the Dp + BZK group was significantly increased compared to that of the control $(p<0.001)$, Dp + vehicle $(p<0.001)$, Dp + PVP-I $(p<0.01)$, and $\mathrm{Dp}+\mathrm{CHG}(\mathrm{p}<0.01)$ groups (Fig. $4 \mathrm{C})$. The Dp + PVP-I and $\mathrm{Dp}+\mathrm{Et}-\mathrm{OH}$ groups also showed a significantly increased eosinophil count compared with the control group ( $p<0.05$ and $p<0.001$, respectively). However, the eosinophil count did not significantly differ among the Dp + PVP-I, Dp + CHG, and Dp + vehicle groups. The eosinophil count of the $\mathrm{Dp}+\mathrm{Et}-\mathrm{OH}$ group was increased relative to that of the Dp + vehicle group, but the difference was not statistically significant. 

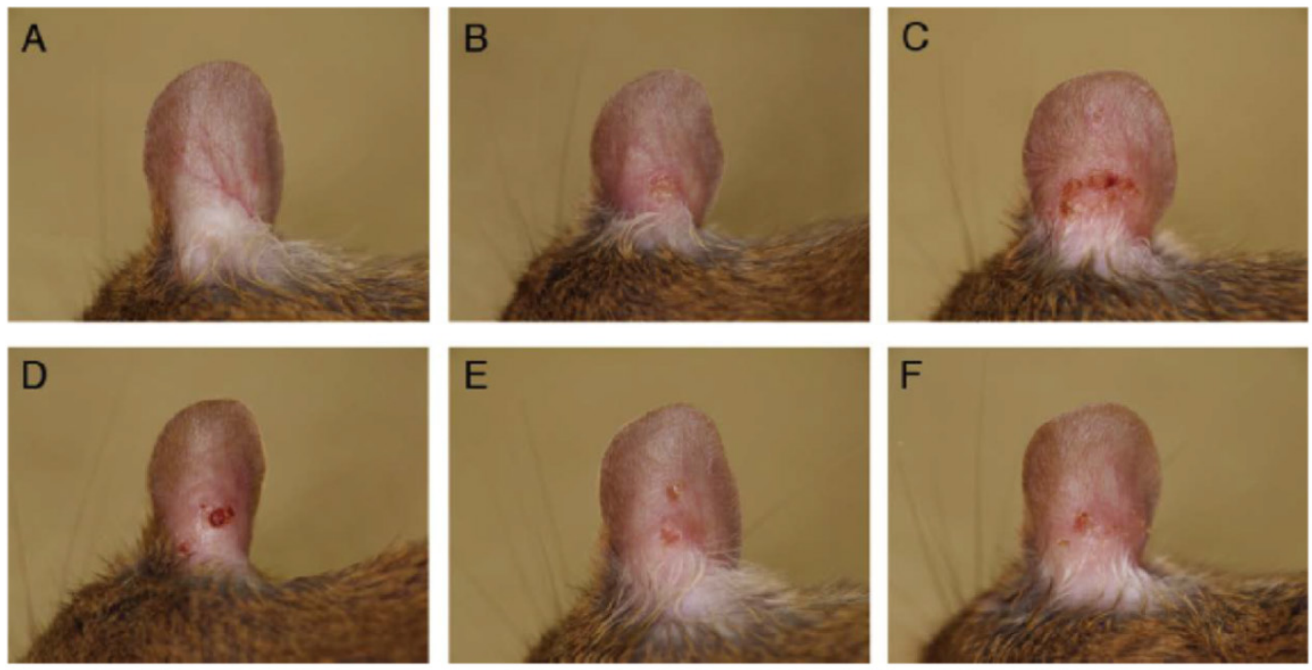

Figure 3. Macroscopic features of atopic dermatitis-like skin lesions (ADSLs) on the right ear at day 18. ADSLs were induced by the injection of $D$. pteronyssinus (Dp) into mouse ear tissue, and the effects of various antiseptics were examined. (A) Saline + vehicle, (B) Dp + vehicle, (C) Dp + BZK, (D) Dp + PVP-I, (E) Dp + Et-OH, and (F) Dp + CHG. No changes were observed in the saline + vehicle group. However, the presence of dryness and erosion were observed in the $\mathrm{Dp}+$ vehicle group. The erosion was most severe in the $\mathrm{Dp}+\mathrm{BZK}$ group, followed by the Dp $+\mathrm{PVP}-\mathrm{I}$ and $\mathrm{Dp}+\mathrm{Et}-\mathrm{OH}$ groups. The clinical changes in the $D p+C H G$ group were similar to those of the $D p+$ vehicle group.

The number of severely degranulated mast cells and total mast cells were significantly increased in the $\mathrm{Dp}+$ vehicle group relative to those in the control group ( $<<0.001$, Fig. 4D), and in the Dp + BZK group compared to those of saline + vehicle $(p<0.001), \mathrm{Dp}+$ vehicle $(p<0.01)$, and Dp + CHG $(p<0.001)$ groups. The Dp + PVP-I and Dp + Et-OH groups showed a significantly increased number of severely degranulated mast cells and total mast cells relative to the control group $(p<0.001)$ but not the $\mathrm{Dp}+$ vehicle group, despite both antiseptic groups displaying relatively higher values for these parameters as compared to the $\mathrm{Dp}+$ vehicle group. The number of severely degranulated mast cells and total mast cells in the Dp + CHG group were significantly increased compared to those of the control group $(p<0.05)$ but not the Dp + vehicle group. The mast cell number was the lowest in the $\mathrm{Dp}+\mathrm{CHG}$ group relative to the other Dp-treated groups. The Dp + CHG group showed significantly reduced numbers of severely granulated mast cells and total mast cells compared to the Dp + PVP-I group ( $p<0.05$ and $p<0.001$, respectively) and $\mathrm{Dp}+\mathrm{Et}-\mathrm{OH}$ group (each $\mathrm{p}<0.05)$.

\subsection{Cytokine and chemokine levels in ear tissue}

The IL- $1 \beta$ levels of the Dp + BZK group were significantly higher than those of the control, $\mathrm{Dp}+$ vehicle, $\mathrm{Dp}+\mathrm{Et}-\mathrm{OH}$, and $\mathrm{Dp}+\mathrm{CHG}$ groups $(\mathrm{p}<$ $0.01)$, and the Dp + PVP-I group ( $p<0.05$, Fig. $5 \mathrm{~A})$. Significant differences in the IL-1 $\beta$ levels were not observed between the other groups. Meanwhile, the IL-33 levels were significantly higher in the Dp-treated groups relative to those of the control group (Fig. 5B), and in the Dp + BZK group relative to those of the $\mathrm{Dp}+$ vehicle and $\mathrm{Dp}+\mathrm{CHG}$ groups $(\mathrm{p}<$ 0.05). However, no differences in IL-33 levels were found between the Dp + PVP-I, Dp + Et-OH, Dp + $\mathrm{CHG}$, and $\mathrm{Dp}+$ vehicle groups. The IL-18 and RANTES levels were increased in the Dp + BZK group compared to the control group $(\mathrm{p}<0.01$ and $\mathrm{p}$ $<0.05$, respectively; Fig. 5C, E) and were increased relative to those of other groups, but the differences were not significant. No significant differences in IL-18 and RANTES levels were observed among the other groups. The profile of MIP-1a mirrored that of IL-1 $\beta$ (Fig. 5D). Compared to the Dp + vehicle group, the antiseptic groups tended to show decreased eotaxin levels (Fig. 5F). This decrease was significantly greater in the Dp + CHG group compared to the Dp + vehicle group $(p<0.05)$. The TNF-a levels were increased in the Dp + BZK and Dp + PVP-I groups compared to the $\mathrm{Dp}+$ vehicle group, but the differences were not significant (Fig. 5G).

\subsection{Production of serum Ig}

Injection of mite allergen tended to increase the total serum IgE (Fig. 6A) and Dp-specific $\operatorname{IgG}_{1}$ (Fig. 6B). The application of BZK markedly induced total IgE production compared with the $\mathrm{Dp}+$ vehicle $(\mathrm{p}<$ 0.001). As well, the application of PVP-I but not Et-OH or CHG tended to increase the total IgE level. The Dp-specific $\operatorname{IgG}_{1}$ level substantially increased with the application of BZK, PVP-I, and Et-OH as compared with $\mathrm{Dp}$ alone, but the overall relative difference was small. The application of CHG did not induce Dp-specific $\operatorname{IgG}_{1}$ production. 


\subsection{Pearson's correlation coefficient analysis}

To investigate the contribution of the evaluated parameters to the clinical scores, Pearson's correlation coefficients were calculated. As shown in Table 1, there were very strong positive relationships between the score for AD-like skin lesions and the number of mast cells, severely degranulated mast cells, and eosinophils, and the levels of MIP-1a and IL-1 $\beta$. There were also strong positive relationships between the score for AD-like skin lesions and the levels of IL-33, IL-18, TNF- $\alpha$, total IgE, and RANTES. However, there was a weak positive relationship between the score for AD-like skin lesions and the level of antigen-specific $\operatorname{IgG}_{1}$, while no relationship was observed with the level of eotaxin.
A

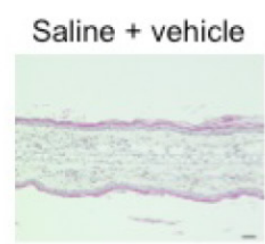

$D p+B Z K$

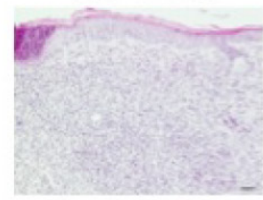

$\mathrm{Dp}+\mathrm{Et}-\mathrm{OH}$

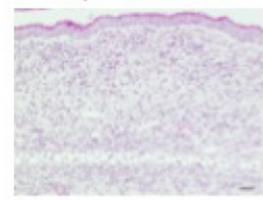

C

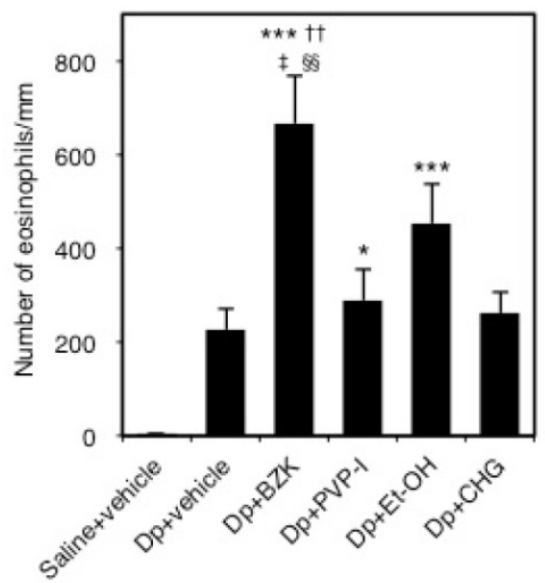

B

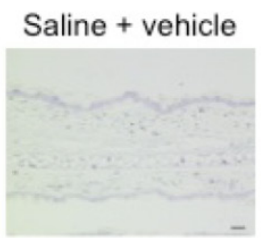

$\mathrm{Dp}+\mathrm{BZK}$

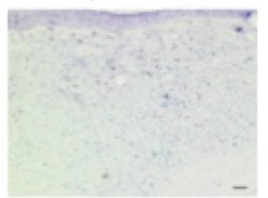

$\mathrm{Dp}+\mathrm{Et}-\mathrm{OH}$

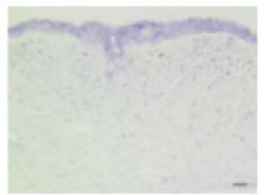

Dp + vehicle

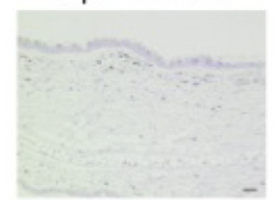

Dp + PVP-I

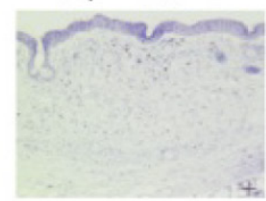

$\mathrm{Dp}+\mathrm{CHG}$
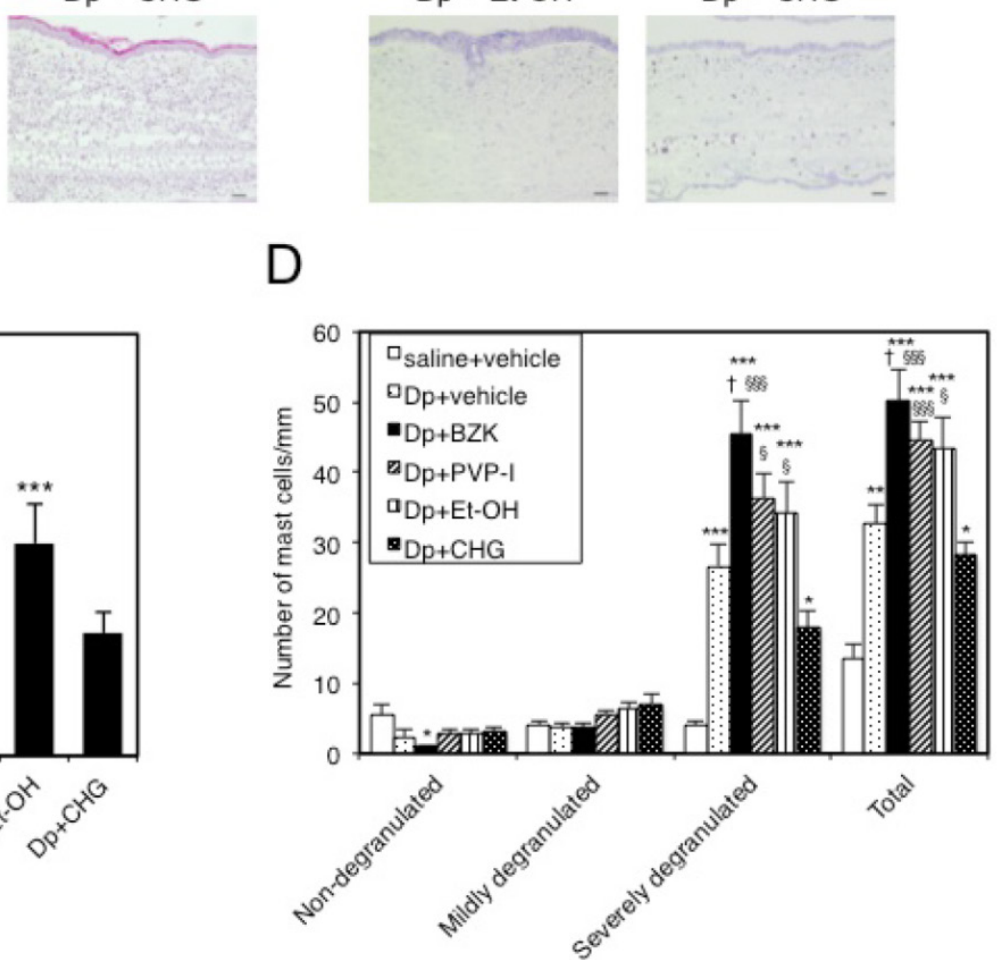

Figure 4. Histological changes in mouse ear tissue on day 18. Microscopic view of ear sections stained with (A) hematoxylin and eosin (HE; scale bar $=40 \mu \mathrm{m}$ ) or (B) toluidine blue (TB; scale bar $=40 \mu \mathrm{m})$. Number of eosinophils $(C)$ and mast cells $(D)$ in ear tissue stained with HE and TB. The numbers of inflammatory cells in 9 areas that extended perpendicularly from the edge of the cartilage of the external ear by a length of $100 \mu \mathrm{m}$ (eosinophils) or 400 $\mu \mathrm{m}$ (mast cells) to the epidermal layer were counted. Mast cells were classified as non-degranulated $(0 \%)$, mildly degranulated $(0-50 \%)$, or severely degranulated $(>50 \%)$ according to the severity of degranulation. Data are the mean \pm SE values of 6 mice in (B) and (C). $* p<0.05$, ** $p<0.01$, and $* * * p$ $<0.001$ vs. saline + vehicle group. $\dagger p<0.01$, and $\dagger \dagger p<0.001$ vs. $D p+$ vehicle group. $\ddagger p<0.01$ vs. $D p+P V P-I$ group. $\S p<0.05, \S \S p<0.01$, and $\S \S \S p$ $<0.001$ vs. $\mathrm{Dp}+\mathrm{CHG}$ group. 
A

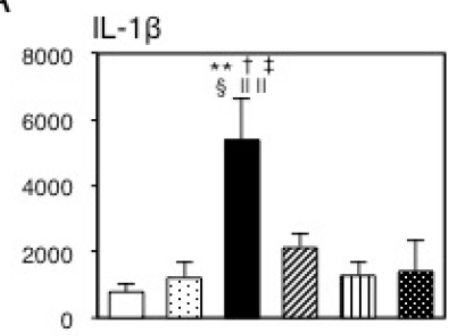

D

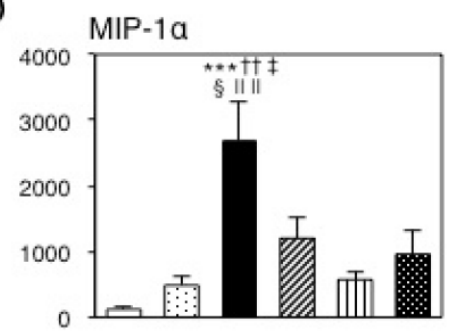

G

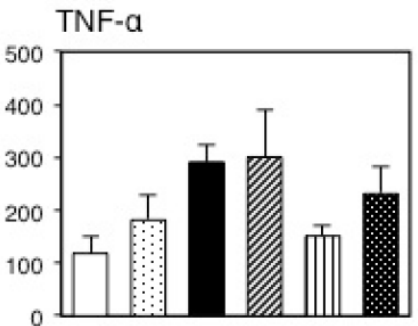

B

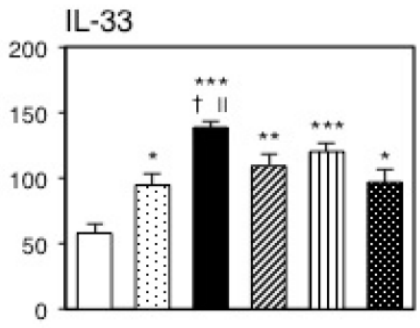

E

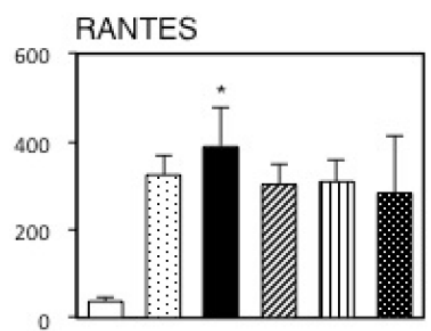

C

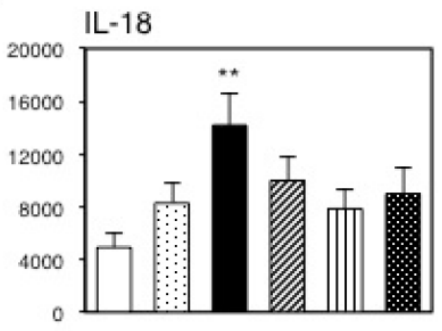

F

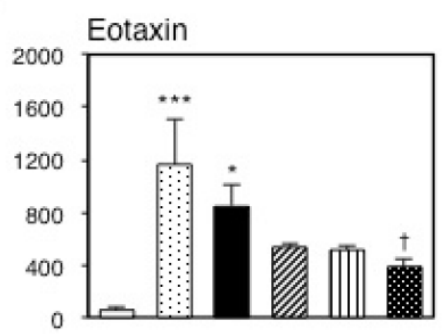

Figure 5. Levels of cytokines and chemokines in mouse ear tissue. After collection, immediate freezing, and homogenization of the ear tissue on the final day of the experiment, the supernatant of the homogenized tissue was used to measure the level of inflammatory proteins via ELISA. Levels of (A) IL-1 $\beta$, (B) IL-33, (C) IL-18, (D) MIP-1 $\alpha$, (E) RANTES, (F) eotaxin, and (G) TNF- $\alpha$. The Y-axis values represent the picograms of each inflammatory protein per milligrams of total ear protein. Data are mean \pm SE values of 6 mice. $* p<0.05$, ** $p<0.01$, and $* * * p<0.001$ vs. saline + vehicle group. $\dagger p<0.01$, and t† $\mathrm{p}<0.001$ vs. $\mathrm{DP}+$ vehicle group. $\ddagger \mathrm{p}<0.05$ vs. $\mathrm{DP}+\mathrm{PVP}-\mathrm{I}$ group. $\S \mathrm{p}<0.01$ vs. $\mathrm{DP}+\mathrm{Et}-\mathrm{OH}$ group. $\| \mathrm{P}<0.05$, and \|\| $\mathrm{P}<0.01$ vs. $\mathrm{Dp}+\mathrm{CHG}$ group.

A

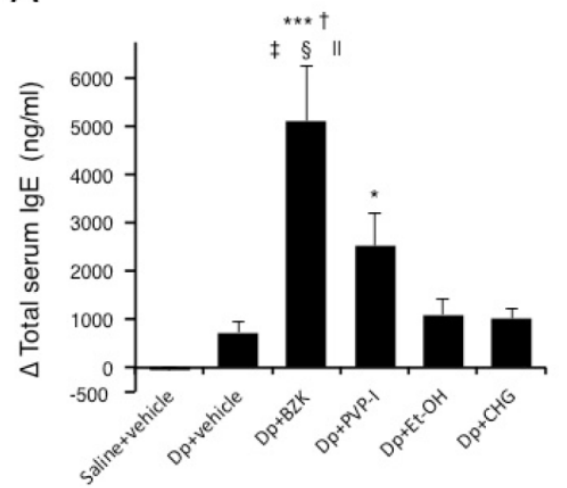

B

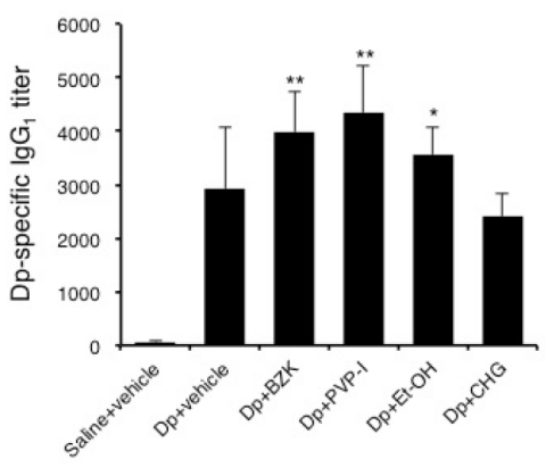

Figure 6. Immunoglobulins levels in the serum of $\mathrm{NC/Nga}$ mice. (A) Total lgE and (B) Dp-specific lgG, levels. Sera were collected by orbital puncture at one day before the first immunization (for $\lg \mathrm{E}$ ) and cardiac puncture on the last day of the experiment (for lgE and $\lg G_{1}$ ), and assayed by ELISA. Results are mean \pm SE values of 12 mice. ${ }^{*} p<0.05, * * p<0.01$, and $* * * p<0.001$ vs. saline + vehicle group. $\dagger p<0.001$ vs. $D p+$ vehicle group. $\ddagger p<0.05$ vs. $D p+P V P-I$ group. $\S p<0.001$ vs. $\mathrm{Dp}+\mathrm{Et}-\mathrm{OH}$ group. $\| \mathrm{p}<0.001$ vs. $\mathrm{Dp}+\mathrm{CHG}$ group.

Table 1. Pearson's correlations between the score for atopic dermatitis-like skin lesions and various evaluated parameters.

\begin{tabular}{|c|c|c|c|c|c|c|c|c|c|c|c|c|}
\hline & Eosinophils & $\begin{array}{l}\text { Total mast } \\
\text { cells }\end{array}$ & $\begin{array}{l}\text { Severely } \\
\text { degranulated } \\
\text { mast cells }\end{array}$ & IL-1 $\beta$ & IL-33 & IL-18 & MIP-1a & RANTES & Eotaxin & TNF- $\alpha$ & $\operatorname{IgE}$ & IgG1 \\
\hline$r$ & 0.752 & 0.818 & 0.812 & 0.720 & 0.694 & 0.647 & 0.786 & 0.485 & 0.281 & 0.636 & 0.622 & 0.299 \\
\hline $\mathrm{p}$ & $<0.001$ & $<0.001$ & $<0.001$ & $<0.001$ & $<0.001$ & $<0.001$ & $<0.001$ & 0.003 & 0.097 & $<0.001$ & $<0.001$ & 0.011 \\
\hline
\end{tabular}

$\mathrm{r}$; Pearson's coefficient of correlation

p; value of significance probability 


\section{Discussion}

In the present study, the application of BZK caused the greatest ADSL aggravation, while CHG application did not result in ADSL aggravation. Although PVP-I and Et-OH also caused some ADSL aggravation, the degree of aggravation was moderate compared to BZK. The application of BZK induced the infiltration of inflammatory cells and increased IL-1 $\beta$, IL-33, IL-18, and MIP-1a levels in subcutaneous tissue and total IgE in serum. The application of PVP-I also increased the infiltration and degranulation of mast cells and increased the TNF-a levels in subcutaneous tissue and IgE levels in serum. The application of Et-OH resulted in the least response, with only an increase in the infiltration of inflammatory cells. Meanwhile, the application of CHG did not induce the infiltration of inflammatory cells or the production of cytokines and chemokines in the subcutaneous tissue and IgE in the sera, when compared to saline alone.

BZK is used at a $0.01-0.2 \%$ concentration in antiseptics for the hands and skin. Although BZK is considered a mild skin antiseptic and is widely used in a number of settings, BZK enhanced the ADSLs most strongly in the present study. Moreover, BZK administration resulted in increased total $\operatorname{IgE}$ and antigen-specific $\mathrm{IgG}_{1}$ production, infiltration and degranulation of inflammatory cells into subcutaneous ear tissue, and cytokine and chemokine levels in the ear tissue. Igs play a role in allergic inflammation, which is induced in part by mast cell and eosinophil degranulation $[19,20]$. The IgE receptors on the surface of mast cells bind to IgE antibody and are cross-linked to the antigen, resulting in degranulation and the release of proinflammatory molecules. Like-

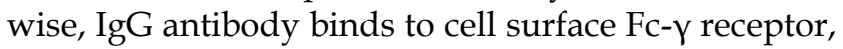
leading to cross-linkage to the antigen and the subsequent release of proinflammatory molecules. The proinflammatory molecules can cause damage to the subcutaneous tissue in $\mathrm{AD}$ or respiratory tract tissue in allergic airway inflammation [21-23]. A few previous studies have examined the role of BZK in immunoglobulin production. Larsen et al. [24] reported the adjuvant effect of BZK and the increased production of antigen-specific IgE and $\operatorname{IgG}_{1}$ following subcutaneous injection. Our results showing the increased production of Igs is consistent with this previous report. Further, the infiltration and degranulation of eosinophils and mast cells at the lesion site indicated the activation of inflammatory cells and Igs induced by the application of BZK contributes to the aggravation of ADSLs in this model.

In the present study, BZK also caused an increase in the IL- 1 family of cytokines (e.g., IL-1 $\beta$,
IL-18, and IL-33) at the lesion site. The IL-1 family is associated with inflammatory skin conditions such as $\mathrm{AD}$, contact dermatitis, psoriasis, and cutaneous lupus erythematosus [25]. IL-18, which is expressed by activated macrophages, epidermal keratinocytes, and dendritic cells, has been shown to contribute to ADSLs in a mouse model of AD [26]. IL-18 also contributes to human $\mathrm{AD}$, and high serum levels of this cytokine have been suggested to be correlated with $\mathrm{IgE}$ levels [27]. Moreover, a study using transgenic mice showed that the accumulation of IL-18 in lesion sites induced ADSLs and that this process was accelerated by the presence of, IL-1 $\beta$, independently of IgE [28]. IL-33 is a new member of the IL-1 family and is highly expressed in keratinocytes, endothelial cells, and the epithelium. The high expression of IL-33 elicits ADSLs with the induction of eosinophils in transgenic mice [29]. In the current study, BZK enhanced the production of the IL-1 family, which likely aggravated the antigen-induced $\mathrm{AD}$ in mice.

The application of BZK also resulted in higher levels of MIP-1a, which acts as a chemoattractant that induces eosinophil chemotaxis to lesions in allergic respiratory diseases [30]. Additionally, MIP-1a levels have been shown to increase in patients with $\mathrm{AD}$ [31] and in mice with ADSLs [32]. In the present study, this chemokine also appears to have contributed to the aggravation of ADSLs in the Dp + BZK group.

Povidone-iodine is commonly used as an antibacterial agent and antiseptic, and has gained widespread acceptance because of its low toxicity and high germicidal efficacy. In this study, the application of PVP-I produced the second most severe aggravation of ADSLs. Moreover, it enhanced the infiltration and degranulation of mast cells in subcutaneous tissue, and tended to increase the production of total $\mathrm{IgE}$, Dp-specific $\operatorname{IgG}_{1}$, TNF- $\alpha$, and MIP-1a in ear tissue. A few studies have examined the effect of PVP-I on mast cells, and the authors have suggested that PVP-I inhibits mast cell degranulation [33, 34]. By contrast, in the present study, the application of PVP-I induced the exacerbation of the ADSLs. This finding suggests the possibility that PVP-I can be an aggravating factor for $\mathrm{AD}$ through inducing the degranulation of mast cells. In AD, the degranulation of mast cells as mediated by TNF- $\alpha$ and histamine induces the expression of intercellular adhesion molecule-1 (ICAM-1) in keratinocytes [35], which is expressed on the vascular endothelium, and is associated with the transmigration of inflammatory leukocytes [36]. The application of PVP-I induced the highest levels of TNF-a production among the test groups, although not to a significant extent. TNF-a may help in the infiltration of mast cells in this group.

PVP-I is used to treat AD, a condition that may 
promote infection by Staphylococcus aureus [37]. Although $S$. aureus has been strongly suggested as an aggravation factor of AD [38, 39], the use of PVP-I might require careful use in the treatment of $\mathrm{AD}$, since it appears to have exacerbated mite-induced $\mathrm{AD}$ in the current study.

The application of Et-OH also tended to increase the ADSLs and infiltration of inflammatory cells, but the other evaluated parameters appeared to be unaffected. Et-OH breaks the skin barrier function, and was found in a previous study to aggravate $\mathrm{AD}$ in an AD mouse model [40]. Hence, our findings are in agreement with the results of this previous study. Further, the present findings suggest that inflammatory cells in the local inflammatory area might contribute to the Et-OH-induced aggravation of ADSLs.

In the present study, the application of CHG resulted in no changes to the mite-induced AD. This result suggests that $\mathrm{CHG}$ might be safely used as an antiseptic in AD patients. However, because CHG can lead to anaphylactic shock [41], caution should be applied in its administration by AD patients.

The results of the Pearson's correlation coefficient analysis indicated the extent of the infiltration of inflammatory cells into subcutaneous tissue was very strongly consistent with the extent of ADSL severity. The MIP-1 $\alpha$ and IL-1 $\beta$ in the lesion sites also contributed to the aggravation of ADSLs. The levels of IL-33, IL-18, TNF- $\alpha$, total IgE, and RANTES were also well correlated with the extent of ADSL severity. The levels of all of these parameters were the highest in the $\mathrm{Dp}+\mathrm{BZK}$ group, with the exception of TNF- $\alpha$, indicating the application of BZK aggravated the ADSL in the mice most strongly. The antiseptic agents PVP-I and Et-OH had a weaker effect than BZK application and did not result in a significant increase of these parameters when compared with the $\mathrm{Dp}+$ vehicle group, with the exception of mast cell infiltration. Thus, the effect of PVP-I and Et-OH application were not as strong as that of BZK. The application of CHG did not contribute to increasing the parameters associated with ADSL aggravation, indicating ADSLs are not exacerbated by CHG.

\section{Conclusions}

The application of BZK to the lesion sites in an AD mouse model markedly aggravated allergen-induced ADSL production. The application of PVP-I and Et-OH also tended to increase ADSLs in this animal model, while the application of CHG did not induce an aggravation of this condition. The results of the current study will help medical staff and food handlers escape the potentially-severe antiseptics to AD.

\section{Acknowledgments}

We wish to thank Professor Tomoko Ito for her helpful advice. This work was supported by MEXT KAKENHI Grant Number 24590753.

\section{Abbreviations}

AD: atopic dermatitis; ADSL: atopic dermatitis-like skin lesion; ANOVA: analysis of variance; BZK: benzalkonium chloride; CHG: chlorhexidine gluconate; Dp: Dermatophagoides pteronyssinus; ELISA: enzyme-linked immunosorbent assay; Et-OH: ethanol; KC: keratinocyte chemoattractant; HSD: honestly significant difference; ICAM-1: intercellular adhesion molecule-1; IFN: interferon; Ig: immunoglobulin; IL: interleukin; MIP: macrophage inflammatory protein; PVP-I: povidone-iodine; RANTES: regulated on activation, normal $\mathrm{T}$ cell expressed and secreted; TNF: tumor necrosis factor.

\section{Competing Interests}

The authors have declared that no competing interest exists.

\section{References}

1. CDC, C.f.D.C.a.P. Guideline for Hand Hygiene in Health-Care Settings; Recommendations of the Healthcare Infection Control Practices Advisory Committee and the HICPAC/SHEA/APIC/IDSA Hand Hygiene Task Force. 2002.

2. Dyer DL, Gerenraich KB, Wadhams PS. Testing a new alcohol-free hand sanitizer to combat infection. AORN J. 1998; 68: 239-41, 243-4, 247-51.

3. Hirayama M. The antimicrobial activity, hydrophobicity and toxicity of sulfonium compounds, and their relationship. Biocontrol Sci Technol. 2011; 16: 23-31.

4. Muller G, Kramer A. Biocompatibility index of antiseptic agents by parallel assessment of antimicrobial activity and cellular cytotoxicity. J Antimicrob Chemother. 2008; 61: 1281-7. doi:10.1093/jac/dkn125.

5. Hann S, Hughes TM, Stone NM. Flexural allergic contact dermatitis to benzalkonium chloride in antiseptic bath oil. Br J Dermatol. 2007; 157: 795-8. doi:10.1111/j.1365-2133.2007.08134.x.

6. Oiso N, Fukai K, Ishii M. Irritant contact dermatitis from benzalkonium chloride in shampoo. Contact Dermatitis. 2005; 52: 54. doi:10.1111/j.0105-1873.2005.0483j.x.

7. Wong DA, Watson AB. Allergic contact dermatitis due to benzalkonium chloride in plaster of Paris. Australas J Dermatol. 2001; 42: 33-5.

8. Lachapelle JM. Allergic contact dermatitis from povidone-iodine: a re-evaluation study. Contact Dermatitis. 2005; 52: 9-10. doi:10.1111/j.0105-1873.2005.00479.x.

9. Murthy MB, Krishnamurthy B. Severe irritant contact dermatitis induced by povidone iodine solution. Indian J Pharmacol. 2009; 41: 199-200. doi:10.4103/0253-7613.56069.

10. Velazquez D, Zamberk P, Suarez R, Lazaro P. Allergic contact dermatitis to povidone-iodine. Contact Dermatitis. 2009; 60: 348-9. doi:10.1111/j.1600-0536.2008.01559.x.

11. Jungbauer FH, van der Harst JJ, Groothoff JW, Coenraads PJ. Skin protection in nursing work: promoting the use of gloves and hand alcohol. Contact Dermatitis. 2004; 51: 135-40. doi:10.1111/j.0105-1873.2004.00422.x.

12. Loffler H, Kampf G, Schmermund D, Maibach HI. How irritant is alcohol? Br J Dermatol. 2007; 157: 74-81. doi:10.1111/j.1365-2133.2007.07944.x.

13. McKenzie SN, Turton P, Castle K, Clark SM, Lansdown MR, Horgan K. Alcohol hand abuse: a cross-sectional survey of skin complaints and usage patterns at a large UK teaching hospital. JRSM Short Reports. 2011; 2: 68. doi:10.1258/shorts.2011.011034.

14. Sharma A, Chopra H. Chlorhexidine urticaria: a rare occurrence with a common mouthwash. Indian J Dent Res. 2009; 20: 377-9. doi:10.4103/0970-9290.57368.

15. Toholka R, Nixon R. Allergic contact dermatitis to chlorhexidine. Australas J Dermatol. 2013; 54: 303-6. doi:10.1111/ajd.12087.

16. McKenzie AN, Culpepper JA, de Waal Malefyt R, Briere F, Punnonen J, Aversa G, et al. Interleukin 13, a T-cell-derived cytokine that regulates human monocyte and B-cell function. Proc Natl Acad Sci U. S. A. 1993; 90: 3735-9. 
17. Takano H, Yanagisawa R, Inoue $\mathrm{K}$, Ichinose T, Sadakane $\mathrm{K}$, Yoshikawa $\mathrm{T}$. Di-(2-ethylhexyl) phthalate enhances atopic dermatitis-like skin lesions in mice. Environ Health Perspect. 2006; 114: 1266-9. doi:10.1289/ehp.8985.

18. Takano H, Yoshikawa T, Ichinose T, Miyabara Y, Imaoka K, Sagai M. Diesel exhaust particles enhance antigen-induced airway inflammation and local cytokine expression in mice. Am J Respir Crit Care Med. 1997; 156: 36-42. doi:10.1164/ajrccm.156.1.9610054.

19. Kaneko M, Swanson MC, Gleich GJ, Kita H. Allergen-specific IgG1 and IgG3 through Fc gamma RII induce eosinophil degranulation. J Clin Invest. 1995; 95: 2813-21. doi:10.1172/JCI117986.

20. Metcalfe DD, Baram D, Mekori YA. Mast cells. Physiol Rev. 1997; 77: 1033-79.

21. Hart PH. Regulation of the inflammatory response in asthma by mast cell

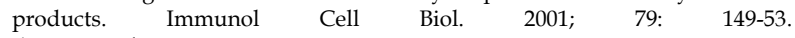
doi:10.1046/j.1440-1711.2001.00983.x

22. Katunuma N, Kido H. Biological functions of serine proteases in mast cells in allergic inflammation. J Cell Biochem. 1988; 38: 291-301. doi:10.1002/jcb.240380408,

23. Steinhoff M, Corvera CU, Thoma MS, Kong W, McAlpine BE, Caughey GH, et al. Proteinase-activated receptor-2 in human skin: tissue distribution and activation of keratinocytes by mast cell tryptase. Exp Dermatol. 1999; 8: 282-94.

24. Larsen ST, Hansen R, Poulsen OM, Nielsen GD. Adjuvant Effect of Benzalkonium Chloride on the Allergen-Specific IgE, IgG1 and IgG2a Antibody Formation in BALB/cJ Mice. Basic Clin Pharmacol Toxicol. 2004; 95: 94-6.

25. Jensen LE. Targeting the IL-1 family members in skin inflammation. Current Opinion in Investigational Drugs. 2010; 11: 1211-20.

26. Terada M, Tsutsui H, Imai Y, Yasuda K, Mizutani H, Yamanishi K, et al. Contribution of IL-18 to atopic-dermatitis-like skin inflammation induced by Staphylococcus aureus product in mice. Proc Natl Acad Sci U. S. A. 2006; 103: 8816-21. doi:10.1073/pnas.0602900103.

27. Shida K, Koizumi H, Shiratori I, Matsumoto M, Kikkawa S, Tsuji S, et al. High serum levels of additional IL-18 forms may be reciprocally correlated with $\operatorname{IgE}$ levels in patients with atopic dermatitis. Immunol Lett. 2001; 79: 169-75.

28. Konishi H, Tsutsui H, Murakami T, Yumikura-Futatsugi S, Yamanaka K, Tanaka M, et al. IL-18 contributes to the spontaneous development of atopic dermatitis-like inflammatory skin lesion independently of $\mathrm{IgE} /$ stat6 under specific pathogen-free conditions. Proc Natl Acad Sci U.S. A. 2002; 99: 11340-5. doi:10.1073/pnas.152337799.

29. Imai $Y$, Yasuda $K$, Sakaguchi $Y$, Haneda $T$, Mizutani $H$, Yoshimoto $T$, et al. Skin-specific expression of IL-33 activates group 2 innate lymphoid cells and elicits atopic dermatitis-like inflammation in mice. Proc Natl Acad Sci U. S. A. 2013; 110: 13921-6. doi:10.1073/pnas.1307321110.

30. Lukacs NW, Standiford TJ, Chensue SW, Kunkel RG, Strieter RM, Kunkel SL. $\mathrm{C}-\mathrm{C}$ chemokine-induced eosinophil chemotaxis during allergic airway inflammation. J Leukocyte Biol. 1996; 60: 573-8.

31. Kaburagi Y, Shimada Y, Nagaoka T, Hasegawa M, Takehara K, Sato S. Enhanced production of CC-chemokines (RANTES, MCP-1, MIP-1alpha, MIP-1beta, and eotaxin) in patients with atopic dermatitis. Archives of Dermatological Research. 2001; 293: 350-5. doi:10.1007/s004030100230.

32. Yanagisawa R, Takano H, Inoue KI, Koike E, Sadakane K, Ichinose T. Size effects of polystyrene nanoparticles on atopic dermatitislike skin lesions in NC/NGA mice. Int J Immunopathol Pharmacol. 2010; 23: 131-41.

33. Abbasoglu O, Sayek I, Hascelik G. Effect of povidone-iodine lavage on peritoneal defence mechanisms in rats. Eur J Surg. 1993; 159: 521-4.

34. Beukelman CJ, van den Berg AJ, Hoekstra MJ, Uhl R, Reimer K, Mueller S. Anti-inflammatory properties of a liposomal hydrogel with povidone-iodine (Repithel) for wound healing in vitro. Burns : journal of the International Society for Burn Injuries. 2008; 34: 845-55. doi:10.1016/j.burns.2007.11.014.

35. Ackermann L, Harvima IT. Mast cells of psoriatic and atopic dermatitis skin are positive for TNF-alpha and their degranulation is associated with expression of ICAM-1 in the epidermis. Archives of Dermatological Research. 1998; 290: 353-9.

36. Carman CV, Springer TA. A transmigratory cup in leukocyte diapedesis both through individual vascular endothelial cells and between them. J Cell Biol. 2004; 167: 377-88. doi:10.1083/jcb.200404129.

37. Sugimoto K, Kuroki H, Kanazawa M, Kurosaki T, Abe H, Takahashi Y, et al. New successful treatment with disinfectant for atopic dermatitis. Dermatology. 1997; 195 Suppl 2: 62-8

38. Hon KL, Lam MC, Leung TF, Kam WY, Li MC, Ip M, et al. Clinical features associated with nasal Staphylococcus aureus colonisation in Chinese children with moderate-to-severe atopic dermatitis. ANNALS Academy of Medicine Singapore. 2005; 34: 602-5.

39. Matsui K, Motohashi R, Nishikawa A. Cell wall components of Staphylococcus aureus induce interleukin- 5 production in patients with atopic dermatitis. J Interferon Cytokine Res. 2000; 20: 321-4. doi:10.1089/107999000312469.

40. Unno $\mathrm{T}$, Suto H, Yoshiike $\mathrm{T}$, Ogawa $\mathrm{H}$, Ra C. Induction of atopic dermatitis-like skin lesion in NC/Nga mice--the influence of the skin barrier destroying solution to the induction of dermatitis. Arerugi. 2001; 50: 1152-62.

41. Okano M, Nomura M, Hata S, Okada N, Sato K, Kitano Y, et al. Anaphylactic symptoms due to chlorhexidine gluconate. Arch Dermatol. 1989; 125: 50-2. 